\title{
Optimizing Feedback Coefficients Of A Practical Synchronous Generator Nonlinear State Observer Using Additional Signals
}

\author{
H. A. Nour Eldin*, F. Fischer*, A. M. Abdel-Hamid** \\ * Group of Automatic Control and Technical Cybernetics, University of Wuppertal, \\ Germany \\ Address: Fuhlrott-Str. 10,42097 Wuppertal, Germany \\ Tel.:0049-0202-4392952,email:eldin@uni-wuppertal.de
}

** Department of Electrical Engineering, Faculty of Engineering, El-Monoufia University, Shebin El-Kom, Egypt (Since 1996 on leave for Post-Doctoral visit at the University of

Wuppertal, Germany)

\begin{abstract}
:
Synchronous generators are characterized by a nonlinearly interacting electrical and mechanical dynamics. Accurate and robust state reconstruction of this machine by an observer should be based on its nonlinear dynamic behavior to avoid intolerable errors. The authors of this paper had published a methodical design of a full order nonlinear observer for turbogenerator systems and organized its experimental validation on a $120 \mathrm{MVA}$ and 1000 MVA synchronous generators at Gud-Power Station in south Munich (Germany) and the Nuclear Power Station of Gösgen (Switzerland). Measured results from these power stations have proved a quite effectiveness of the proposed methodology on getting a stationary robust state reconstruction. However, some transient results are characterized with state oscillations. To prevent such transient oscillations, this paper introduces an optimum technique for the selection of the observer feedback constants. Moreover, additional signals, such as real, reactive and apparent power as well as the amplitude of the stator current are used for the observer feedback. These signals have proved to enhance damping of the observer states transient oscillations.
\end{abstract}

\section{Introduction}

A considerable interest has been directed for state estimation techniques in power systems [1-4,17-27]. Much attention has been given to the design of observer-controllers for excitation and/or governor systems $[18,19,23,24]$. The observers are mainly designed, in this field, to estimate nondirectly measurable state variables like the generator angle $(\delta)$ and the stator current components $\left(i_{d}, i_{q}\right)$ using measurable ones. Most of the publications in this area employ either a reduced order generator model or a linearized equations of the turbogenerator

Manuscript received from Dr: A. M. Abdel-Hamid at: 15/10/1997, accepted at: $11 / 5 / 1998$, Engineering research bulletin, Vol. 21, No. 2, 1998, Menoufiya University, Faculty of Engineering, Shebin El- Kom, Egypt, ISSN. 1110-1180. 
model around a nominal operating point [17-20]. These observers fail in estimating the unmeasurable state variables if the external disturbances are increased or the operating conditions are changed. Also, it is not clear how robust are these observers with respect to various types of power system faults. The first nonlinear observer of Osman and Nour Eldin [1] applies the complete nonlinear $7^{\text {th }}$ order model of the synchronous generator and shows robustness against network voltage disturbances, network impedance disturbances as will as driving torque changes. The proposed nonlinear observer have proved to give an exact estimation of the internal states, such as rotor currents, the polar angle, the polar voltage and the stator and rotor fluxes, of the turbogenerator system $[1-5,21,22,25,27]$. The performance of this nonlinear observer is advantageous due to its independence on the present operating point. Therefor, there is no need to update the observer

parameters through parameter estimation techniques or using adaptive feedback. The observer have also proved to be neutral in different control applications. In Osman and Nour Eldin [1-3] an excitation system for the synchronous generator is designed using signals from the nonlinear observers and has proved to be effective. Also, this observer has been applied to generate the necessary signals required for damping subsynchronous resonance oscillations (SSR) [25]. Different control strategies such as excitation control system, static var compensators (SVC), and combined controllers of excitation and SVC systems were also applied with feedback signals from the nonlinear observer and resulted in a very acceptable SSR damping performance [25].

The proposed observer for the synchronous generator is a nonlinear one with constant feedback. It has been shown that pole assignment can be used to determine exactly the feedback constants of electrical state reconstruction [1-4]. Unfortunately, the slow mechanical states are highly nonlinear which means that the above pole assignment technique couldn't be applied to calculate the feedback constants for this part. To solve this problem the authors of this paper have proposed two methodologies, whose results are to be published recently, to help finding the observer feedback constants for the mentioned slow mechanical states. The first methodology depends on applying Liapunov's stability theorems. A second order Liapunov function is introduced. Based on the energy interpretations of its terms, the necessary and sufficient conditions for the asymptotic stability of this nonlinear observer are derived. The second one applies an estimation procedure in order to find out the real stability region in parameter space of the proposed full order nonlinear observer. Though these methods are necessary for analyzing the overall system stability and give very important hints on the boards of the machine as well as the nonlinear observer stability, they can't be used to determine exactly the values of the feedback constants for the state reconstruction of the nonlinear mechanical part. Trial and error procedures to select these feedback constants within the boards derived from the above methodologies have proved inefficiency and are sometimes accompanied by oscillations in observer states especially in transient conditions. To prevent such transient oscillations, this paper introduces an optimum technique for the selection of the observer feedback constants. Moreover, additional signals, such as real, reactive and apparent power as well as the amplitude of the stator current are used for the observer feedback. These signals have proved to enhance damping of the observer states transient oscillations.

\section{The synchronous generator model}

Figure (1) shows a synchronous generator which is connected to an infinite bus through a rigid network. The generator model used is the complete $7^{\text {th }}$ order (Park's model). This has been chosen in order to develop a nonlinear state reconstruction observer for the synchronous generator for which reduced models are not exactly representative. The complete model of the synchronous generator connected to a rigid network is documented in [1-16]. The model can be viewed as consisting of an electrical and a mechanical subsystems. The electrical part describes the stator, rotor and field currents while the mechanical subsystem describes the generator slip and the power angle. Both these subsystems are nonlinearly interconnected through the electrical moment and the polar angle. Consequently, the complete model of the 
synchronous generator connected to the rigid network through an external imedance $Z_{e}$ can be given by the following equations:

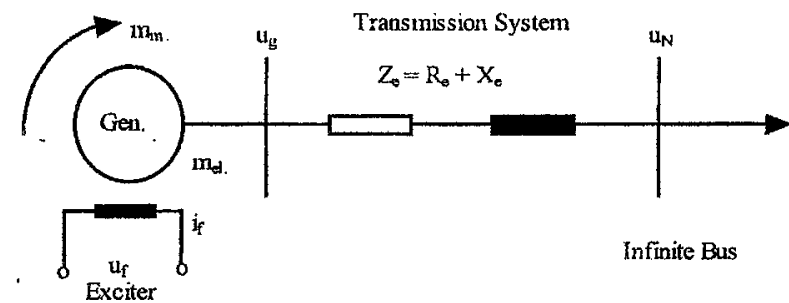

Figure (1) Synchronous Generator Model Connected To Infinite Bus

\subsection{The electrical subsystem}

$L \frac{d}{d t} i=R \underset{-}{i+n} u_{f}+\underline{-u}_{-N}(d) U_{N}$

where:

$\underline{i}=\left[\begin{array}{lllll}i_{f} & i_{d} & i_{D} & i_{q} & i_{Q}\end{array}\right]^{T}$

$\underline{n}_{f}=\left[\begin{array}{lllll}1 / T_{f} & 0 & 0 & 0 & 0\end{array}\right]^{T}$

$\underline{u}_{n}(d)=\left[\begin{array}{lllll}0 & \sin (d) & 0 & \cos (d) & 0\end{array}\right]^{T}$

The matrices $L, R$ are given in the appendix

\subsection{The mechanical subsystem}

$\frac{d}{d t} s=\frac{1}{T_{m}}\left(m_{m}-m_{e l}\right)$

$\frac{d}{d t} \delta=\omega s$

where

$m_{e l}=i_{f} i_{q}+\left(x_{d}-x_{q}\right) i_{d} i_{q}-\left(i_{d} i_{Q}-i_{D} i_{q}\right)$

\subsection{Internal variables}

Flux

$\Psi=L i(t)$

where

$\Psi=\left[\begin{array}{lllll}\Psi_{f} & \Psi_{d} & \Psi_{D} & \Psi_{q} & \Psi_{Q}\end{array}\right]$

Polar voltage

$u_{p}=\sqrt{u_{p d}^{2}+u_{p q}^{2}}$ 


$$
\begin{aligned}
& {\left[\begin{array}{l}
u_{p d} \\
u_{p q}
\end{array}\right]=\frac{1}{\omega}\left[\begin{array}{cc}
x_{d}+x_{e} & 0 \\
0 & x_{q+} x_{e}
\end{array}\right] \frac{d}{d t}\left[\begin{array}{l}
i_{d} \\
i_{q}
\end{array}\right]+} \\
& {\left[\begin{array}{cc}
r+r_{e} & -\left(x_{q}+x_{e}\right) \\
x_{d}+x_{e} & r+r_{e}
\end{array}\right]\left[\begin{array}{l}
i_{d} \\
i_{q}
\end{array}\right]+\left[\begin{array}{c}
\sin (\delta) \\
\cos (\delta)
\end{array}\right] u_{N}}
\end{aligned}
$$

\subsection{External variables}

Generator voltage

$$
u_{g}=\sqrt{u_{g d}^{2}+u_{g q}^{2}}
$$

$\left[\begin{array}{l}u_{g d} \\ u_{g q}\end{array}\right]=\frac{x_{e}}{\omega} \frac{d}{d t}\left[\begin{array}{l}i_{d} \\ i_{q}\end{array}\right]+$

$\left(\left[\begin{array}{cc}r_{e} & 0 \\ 0 & r_{e}\end{array}\right]+(1+s)\left[\begin{array}{cc}0 & -x_{e} \\ x_{e} & 0\end{array}\right]\right)\left[\begin{array}{l}i_{d} \\ i_{q}\end{array}\right]+$ $\left[\begin{array}{c}\sin (\delta) \\ \cos (\delta)\end{array}\right] u_{N}$

Generator active power

$P_{g}(t)=u_{g d}(t) i_{d}(t)+u_{g q}(t) i_{q}(t)$

Generator reactive power

$Q_{g}(t)=u_{g q}(t) i_{d}(t)-u_{g d}(t) i_{q}(t)$

Equations $(1.1, \ldots, 1.7)$ and $(2.1, \ldots, 2.8)$ build the complete dynamic model of synchronous generator connected to a rigid network. All state variables, internal and external variables of the generator can be computed and simulated $[1-5,21,22,25,27]$.

\section{The nonlinear state observer for the synchronous generator}

Generally, state reconstruction observers use a copy of the system model equations to generate the reconstructed states. By appropriate feedback the output estimation error and the resulting state error asymptotically vanishes. The state reconstruction observer for the synchronous generator that will be used in this paper ( Fig. 2 ) is a nonlinear observer with a constant feedback matrix. It has been shown in $[1-5,21,22,25,27]$ that the electrical and the mechanical parts can be regarded independently of each other. 


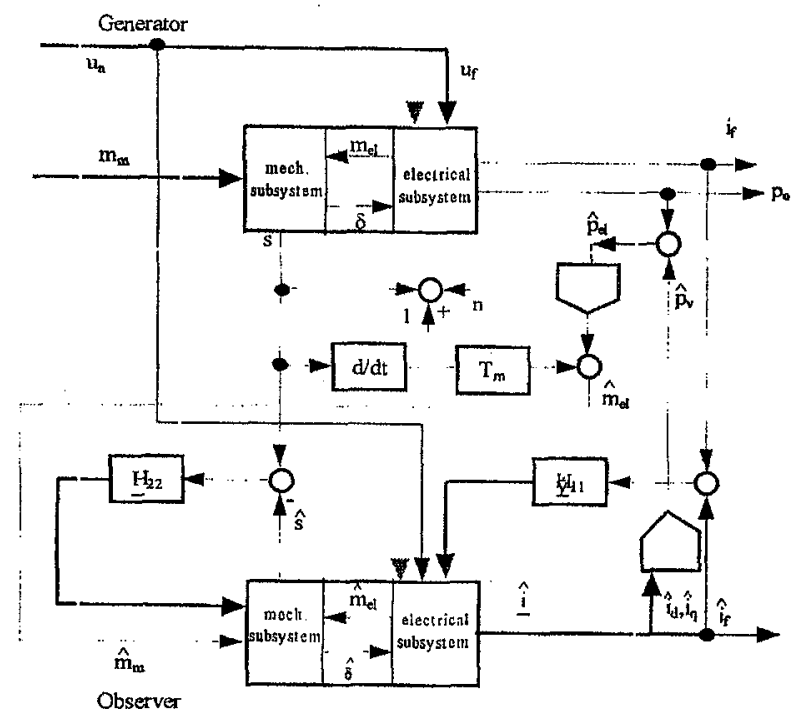

Figure (2) The synchronous generator model and its nonlinear state observer

For the electrical part, the suitable measured state which guarantees global and local observability is the field current. It has been also shown that the well established pole assignment technique can be used to obtain the feedback coefficients $[1-5,21,22,25,27]$ and insure that the reconstruction error for this electrical part asymptotically vanishes. In the mechanical dynamics side, measured slip serves as the measured variable. In a paper under publication, the authors have introduced a Liapunov's stability based technique to find out the boards of the corresponding feedback parameters for this "slow" mechanical subsystem. However, this paper presents an optimum technique for the precise selection of these feedback constants. Moreover, additional signals, such as real, reactive and apparent power as well as the amplitude of the stator current are used for the observer feedback. These signals have proved to enhance damping of the observer states transient oscillations.

The equations for the nonlinear state observer for the turbugenerator $[1-5,21,22,25,27]$ are:

$$
\begin{aligned}
& \frac{d}{d t} \hat{i}=L^{-1} R \hat{i}+L^{-1}[\underset{-f}{n} \underset{-n}{n}(\hat{\delta})] \underset{-}{u}+H_{11}\left(i_{f}-\hat{i_{f}}\right) \\
& \frac{d}{d t} \hat{s}=\frac{1}{T_{m}}\left[\hat{m}_{m}-\hat{m}_{e l}\right]+h_{62}(s-\hat{s}) \\
& \frac{d}{d t} \hat{\delta}=\omega \hat{s}+h_{72}(s-\hat{s})
\end{aligned}
$$

Where

$$
\begin{aligned}
& \hat{i}=\left[\begin{array}{lllll}
\hat{i_{f}} & \hat{i_{d}} & \hat{i_{D}} & \hat{i_{q}} & \hat{i_{Q}}
\end{array}\right]^{T} \\
& \underset{-f}{n}=\left[\begin{array}{lllll}
\frac{1}{T_{f}} & 0 & 0 & 0 & 0
\end{array}\right]^{T} \\
& \underline{n}_{n}(\hat{\delta})=\left[\begin{array}{lllll}
0 \sin (\hat{\delta}) & 0 & \cos (\hat{\delta}) & 0]^{T}
\end{array}\right.
\end{aligned}
$$




$$
\begin{aligned}
& \hat{m}_{e l}=\hat{i}_{f} \hat{i}_{q}+\left(x_{d}-x_{q}\right) \hat{i}_{d} \hat{i}_{q}+\left(\hat{i}_{d} \hat{i}_{Q}-\hat{i}_{D} \hat{i}_{q}\right) \\
& \underline{u}=\left[\begin{array}{ll}
u_{f} & u_{N}
\end{array}\right]^{T} \\
& \underset{-11}{\mathrm{H}}=\left[\begin{array}{lllll}
\mathrm{h}_{11} & \mathrm{~h}_{21} & \mathrm{~h}_{31} & \mathrm{~h}_{41} & \mathrm{~h}_{51}
\end{array}\right]^{\mathrm{T}} \\
& \underline{-}_{22}=\left[\begin{array}{ll}
h_{62} & h_{72}
\end{array}\right]^{T}
\end{aligned}
$$

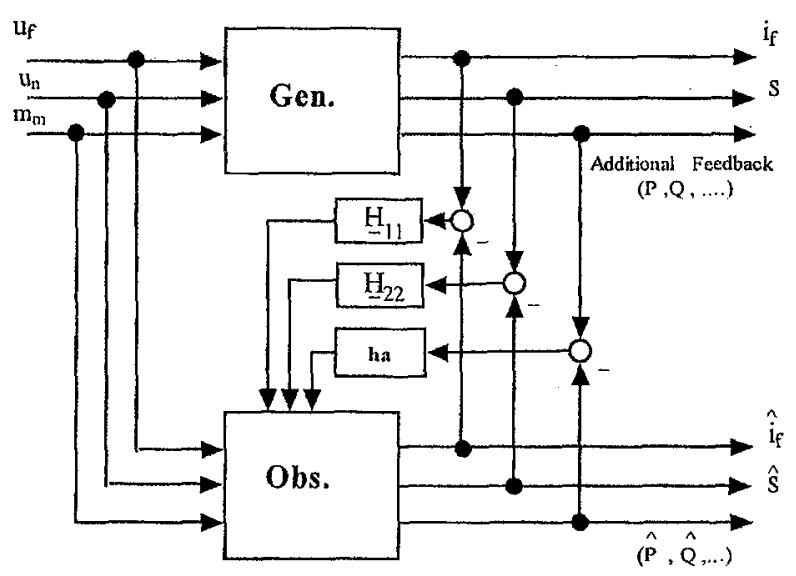

Figure (3) Additinal feedback variables

\section{Multidimensional Optimization Methods}

The purpose of this study is to find out the feedback coefficients of the nonlinear observer based on optimum methods. Also, additional feedback signals are used to prevent observer states transient oscillations. In both cases, it is required to find out a specitic number of input variables which minimizes the difference between the reference and actual values of the oscillatory states of the nonlinear observer. Such difference will be calculated as integration of the sum of weighted differences in a form like:

$$
f(x)=\sum_{i=0}^{t_{\text {imax }}} t_{i}^{p} \sum_{j=0}^{m} W_{j}\left|y_{j}-\hat{y}_{j}\right|^{q}
$$

where:

$f(. .):$. is the objective function.

$\underline{x} \quad:$ is an $n$-dimensional input vector.

$t_{\text {imax }}:$ is the time during which the reference value is kept constant.

$p \quad:$ is exponent of the weighting time.

$\mathrm{y} \quad$ : is an m-dimensional reference vector.

$-$

$\mathrm{y} \quad$ : is an m-dimensional observer vector.

$\underline{w}:$ is an m-dimensional weighting vector.

$q$ : evaluation of the difference ( $q=1$ for the value, $q=2$ for the quadratic difference) 
In the above equation (4.1), the integration will be digitally calculated. Therefor, a sum form is used instead of an integral one. Several methods may be found in the letrature[28-31] for the purpose of multidimensional optimization. In this study, two algorithms are implemented to optimize eqn. (4.1). A summary of them can be explained as follows:

\subsection{Pattern-Search-Algorithm}

The pattern search method is usually used to optimize nonlinear complex systems. In this study some modifications are performed to realize its practical implementation. At first an output point "e.g. $\mathrm{P}_{0}$ " of the optimization have to be selected. In order to achieve a minimized objective function, this point will be described through an $\mathrm{n}$-dimensional vector " $\underline{x "}$ whose components are considered to be variable parameters. Beginning from a basis point " $B_{j}$ ", a local search for the direction at which the object function is reduced will be started. Accordingly an $n$-number of search trials with corresponding " $x_{j}, j=1 \ldots n$ " in both positive and negative directions are processed around a step width of " $S_{i j}$ ". This leads to a decision about the objective function tendence. If the objective function is becoming reduced, then it means that one have achieved a successful step toward optimization. Consequently, the search process of the parameter " $x_{j+1}$ " will be started from the resulted new improved basis point

The successful search trails vector of the " $\mathrm{i}^{\text {th }}$ " optimization steps may be expressed as follows:

$v_{-i}=\left(v_{i 1}, v_{i 2}, \ldots, v_{i n}\right)^{T}$

with

$$
v_{i j}=\left\{\begin{array}{c}
+S_{i j} \\
o \\
-S_{i j}
\end{array}\right.
$$

where: $+S_{i j}$ is a search movement in the positive successful direction.

$: 0$ is unsuccessful search movement.

where: $-S_{i j}$ is a search movement in the negative successful direction.

Such vector helps to construct and modify the pattern at which the strongest reduction of the objective function in an n-dimensional space and consequently finding out the most probable successful optimization step direction.

The vector of search step " $S_{p / i}$ " includes a series of past informations about the search trial movements and above all those successful pattern steps. An alternative search step " $\underline{S}_{p 2 i}$." will be necessary only if the search step " $S_{p l i}$ " doesn't lead to any successful tendency. Following are constraints to the search step:

$\underline{S}_{p l i}=\underline{S}_{p i+1}+f^{*} \underline{v}_{i}$

$\underline{S}_{p 2 i}=f^{*} \underline{v}_{i}$

where:

$\underline{S}_{p i j}:$ Pattern search vector (for the $i$-th

optimization step) 
$S_{p ?_{i+1}}:$ Previously used pattern search step vector

$$
\left(\underline{S}_{p l i+1}, \text { or } \underline{S}_{p 2 i+1} \text { or } \underline{Q}\right)
$$

$f:$ Scalar value $\geq 1$, free selective (in [28]; $f=2$ )

$v_{i}$ : Vector of successful trail movements (for the $i$-th

optimization step)

One should note that a great improvement to the objective function minimization depends essentially on the search step width " $S_{i j}$.". A convergence improvement may be obtained if the search step width is enlarged. This can be detected if, in case of successful search, the variation of the objective function is no longer be remarkable. However, a maximum limits of the step width have to be considered.

\subsection{Direction Set-(Powell-) Algorithm}

Details of this method can be found in [30,31]. The used algorithm works essentially as previously mentioned in pattern search method with the difference that the minimization begins from a starting point and go forward in one direction. In this study the method is applied with additional minimization to the search trial movements and consequently optimizing the pattern steps.

\section{Experimental Implementation And Results}

In this work a realization of the synchronous machine nonlinear observer on a laboratory transputer system has been performed. The necessary measurements has been taken from a 120 MVA and 1000 MVA synchronous generators at Gud-Power Station in south Munich (Germany) and the Nuclear Power Station of Gösgen (Switzerland). The measured data are stored as look up tables to be processed from the developed simulation CAD-program package. Details of on line realization of the software package on a transputer network can be found in [32]. This paper is concerned essentially to the effect of additional feedback from real, reactive and apparent power as well as the amplitude of the stator current on the optimization process. The main objective is to minimize the observer states transient oscillations. The results of an example of experimental implementation on a Gas-turboGenerator is given in the following.

As previously mentioned, some transient results are characterized with state oscillations. This is clear from the curves of Fig.4. To prevent such transient oscillations, this paper introduces an optimum technique for the selection of the observer feedback constants. At first additional signals are added in the feedback loop as shown in Fig.3. The previously explained optimization algorithms are applied for different switching cases (and consequently different machine operating data) with an objective function as that given in Eq.(4.1) which is described with weighting sums of the oscillatory field current, reactive power, active power and slip. The value of the objective function with and without additional signals will be compared for every additional feedback signal. This allows to find out which additional signal is mostly effective. Results of this test for different additional signals is summarized in Tables (1-a), (1-b), (1-c), and (1-d). The heading symbols used in these tables can be explained as follows:

SC1-SC8: Experimental Switching Cases, e.g., stepping positions, voltage variations...etc,

For example:

SCl: Represent a practical switching case of stepping the transformer from position $3 \rightarrow 4$. 
Table (1-a) Active power used as additional feedback

\begin{tabular}{|c|c|c|c|c|c|c|c|c|c|}
\hline & $\mathrm{SC} 1$ & $\mathrm{SC2}$ & SC3 & $\mathrm{SC4}$ & SC5 & $\mathrm{SC6}$ & SC7 & SC8 & AV \\
\hline hal & -3.4 & -3.9 & -12.6 & -2.15 & -6.3 & -20.3 & -1.6 & -5.6 & -5.65 \\
\hline ha2 & 0.3 & 0.25 & 4.45 & 1.95 & 0.8 & 0.05 & 2.4 & 0.03 & 0.96 \\
\hline ha3 & 0.9 & 1.35 & 0.1 & 2.03 & 2.15 & 9.15 & 0.5 & 0.7 & 1.27 \\
\hline ha4 & -1.7 & -1.6 & -12.4 & -2.3 & 4.7 & 32.3 & 0.1 & 1.0 & 0.03 \\
\hline has & -0.4 & -0.8 & 38.4 & 5.2 & 5.5 & 1.7 & -1.35 & -1.6 & 1.73 \\
\hline ha6 & 0.18 & 0.2 & 0.73 & 0.28 & 0.13 & 1.7 & 0.58 & 0.39 & 0.39 \\
\hline ha7 & 8.0 & 6.4 & 36.8 & 11.9 & 17.5 & 68.9 & 8.3 & 6.6 & 14.85 \\
\hline $\mathrm{OF}_{v}$ & 0.4356 & 0.4590 & 1.5601 & 1.6645 & 0.5086 & 0.6724 & 2.5408 & 2.2377 & \\
\hline (2) & 02607 & 16.584 & $6,3,8,82=1$ & 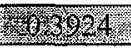 & 0.0666 & 008110 & 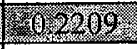 & 12211: & $y^{2}$ \\
\hline$I_{\text {opt. }}$ & 0.3688 & 0.3686 & 0.2363 & 0.2358 & 0.1309 & 0.1214 & 0.0869 & 0.0944 & 0.2016 \\
\hline $\mathrm{OF}_{A V}$ & 0.1702 & 0.1730 & 0.3871 & 0.3992 & 0.1134 & 0.1292 & 0.1833 & 0.1745 & \\
\hline$I_{A V}$ & 0.3906 & 0.3769 & 0.2481 & 0.2398 & 0.2229 & 0.1921 & 0.0721 & 0.0780 & 0.2275 \\
\hline
\end{tabular}

Table (1-b) Reactive power used as additional feedback

\begin{tabular}{|c|c|c|c|c|c|c|c|c|c|}
\hline & $\mathrm{SC1}$ & SC2 & SC3 & SC4 & SC5 & SC6 & SC7 & SC8 & $\mathrm{AV}$ \\
\hline hal & 2.9 & 4.8 & 2.5 & 3.85 & 2.9 & 3.25 & 4.3 & 7.5 & 3.67 \\
\hline ha2 & -0.28 & -1.55 & -2.2 & -2.1 & -0.64 & -0.35 & -2.1 & -1.55 & -1.38 \\
\hline ha3 & -0.76 & -2.85 & -1.13 & -0.85 & -1.53 & -0.06 & -2.3 & -1.63 & -1.37 \\
\hline ha4 & 6.5 & 1.1 & -1.8 & -1.4 & 7.6 & -1.9 & -0.3 & 3.3 & 1.23 \\
\hline ha5 & 6.5 & 3.7 & 0.7 & -2.3 & -0.2 & 2.33 & -1.0 & -6.3 & 1.01 \\
\hline ha6 & -0.29 & -0.23 & -0.23 & -0.15 & -0.18 & -0.11 & -0.5 & -0.53 & -0.26 \\
\hline ha7 & -2.3 & -22.5 & -23.7 & -23.6 & -11.7 & -19.9 & -25.1 & -26.1 & -21.1 \\
\hline $\mathrm{OF}_{v}$ & 0.4356 & 0.4590 & 1.5601 & 1.6645 & 0.5086 & 0.6724 & 2.5408 & 2.2377 & \\
\hline OrF & 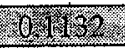 & 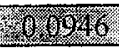 & 6028,8 & (a) 296 & 1010410 & 0,1020 & 6 $2 \times 146$ & 102 2 - & 18 \\
\hline$I_{\text {opt. }}$ & 0.2598 & 0.2061 & 0.1819 & 0.1379 & 0.0807 & 0.1517 & 0.0845 & 0.0950 & 0.1497 \\
\hline $\mathrm{OF}_{\mathrm{AV}}$ & 0.1402 & 0.1238 & 0.3190 & 0.2716 & 0.0481 & 0.1141 & 0.2705 & 0.2481 & \\
\hline$I_{A V}$ & 0.3218 & 0.2697 & 0.2044 & 0.1632 & 0.0946 & 0.1697 & 0.1065 & 0.1109 & 0.1801 \\
\hline
\end{tabular}

Table (1-c) Apparent power used as additional feedback

\begin{tabular}{|c|c|c|c|c|c|c|c|c|c|}
\hline & SC1 & $\mathrm{SC} 2$ & SC3 & SC4 & SC5 & SC6 & SC7 & $\mathrm{SC} 8$ & AV \\
\hline hal & -1.15 & -1.65 & -5.4 & -12.1 & -8.6 & -3.5 & -7.55 & -3.6 & -5.05 \\
\hline ha2 & 1.05 & 1.95 & 1.15 & 0.7 & 2.6 & 1.2 & 1.1 & 1.05 & 1.25 \\
\hline ha3 & 1.25 & 0.08 & 1.8 & -1.13 & 0.18 & 1.75 & 6.3 & 0.29 & 0.89 \\
\hline ha4 & 2.5 & 0.2 & 0.0 & 0.7 & 9.5 & 2.7 & 2.2 & -0.4 & 1.38 \\
\hline ha5 & -4.3 & 0.6 & 0.0 & 0.7 & -0.5 & 7.9 & 8.1 & -1.6 & 1.18 \\
\hline ha6 & 0.15 & 0.1 & 0.5 & 0.36 & 0.18 & 0.4 & 0.83 & 0.38 & 0.33 \\
\hline ha7 & 7.9 & 8.2 & 15.2 & 21.7 & 21.4 & 15.3 & 24.5 & 5.8 & 15.0 \\
\hline $\mathrm{OF}_{\mathrm{v}}$ & 0.4356 & 0.4590 & 1.5601 & 1.6645 & 0.5086 & 0.6724 & 2.5408 & 2.2377 & \\
\hline 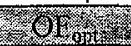 & - 2,294 & 02301 & (6) 347 & $103 / 11$ & 00088 & 0.17098 & (1) 1481 & $12^{2} 2_{2}$ & \\
\hline$I_{\text {opt. }}$ & 0.6310 & 0.5019 & 0.2274 & 0.2049 & 0.1739 & 0.1491 & 0.0583 & 0.1171 & 0.2580 \\
\hline$O F_{\mathrm{AV}}$. & 0.2751 & 0.2436 & 0.3467 & 0.3743 & 0.1730 & 0.1255 & 0.1954 & 0.1931 & \\
\hline$I_{A V}$ & 0.6314 & 0.5308 & 0.2222 & 0.2249 & 0.3402 & 0.1867 & 0.0769 & 0.0863 & 0.2874 \\
\hline
\end{tabular}

Table (1-d) Power angle used as additional feedback

\begin{tabular}{|c|c|c|c|c|c|c|c|c|c|}
\hline & SC1 & SC2 & SC3 & $\mathrm{SC4}$ & SC5 & SC6 & SC7 & SC8 & $\mathrm{AV}$ \\
\hline ha1 & 2.85 & 0.75 & 0.98 & 3.05 & 2.88 & 0.83 & 3.4 & 2.01 & 1.58 \\
\hline ha2 & -0.48 & -2.5 & -0.98 & -0.88 & -0.87 & -0.36 & -2.08 & -2.06 & -0.92 \\
\hline ha3 & -0.98 & -0.24 & -1.1 & -0.73 & -0.75 & -0.5 & -3.34 & -3.13 & -0.90 \\
\hline ha4 & -0.4 & 1.43 & 0.22 & 1.91 & 2.1 & -0.43 & 0.9 & -0.31 & 0.47 \\
\hline ha5 & 7.9 & 4.44 & -1.51 & -5.89 & 1.0 & 0.47 & -3.45 & -1.03 & 0.12 \\
\hline ha6 & -0.13 & -0.16 & -0.06 & -0.1 & -0.15 & -0.03 & -0.49 & -0.28 & -0.11 \\
\hline ha7 & -11.7 & -11.5 & -14.8 & -14.8 & -11.3 & -12.3 & -27.3 & -26.2 & -11.4 \\
\hline$O F_{v}$ & 0.4355 & 0.4587 & 1.5599 & 1.6645 & 0.5085 & 0.6724 & 2.5408 & 2.2377 & \\
\hline (101) & 96161 & 196 & (1) 1950 & 0.2441 & 10968 & 3. & 2176 & (1978 & \\
\hline$I_{\text {opt. }}$ & 0.2252 & 0.1974 & 0.1942 & 0.1466 & 0.0769 & 0.1517 & 0.0707 & 0,0811 & 0.1429 \\
\hline$O F_{A V}$ & 0.1044 & 0.1101 . & 0.3102 & 0.2513 & 0.0421 & 0.1066 & 0.1833 & 0.1892 & \\
\hline$I_{A V}$ & 0.2396 & 0.2399 & 0.1988 & 0.1509 & 0.0828 & 0.1585 & 0.0721 & 0.0845 & 0.1534 \\
\hline
\end{tabular}



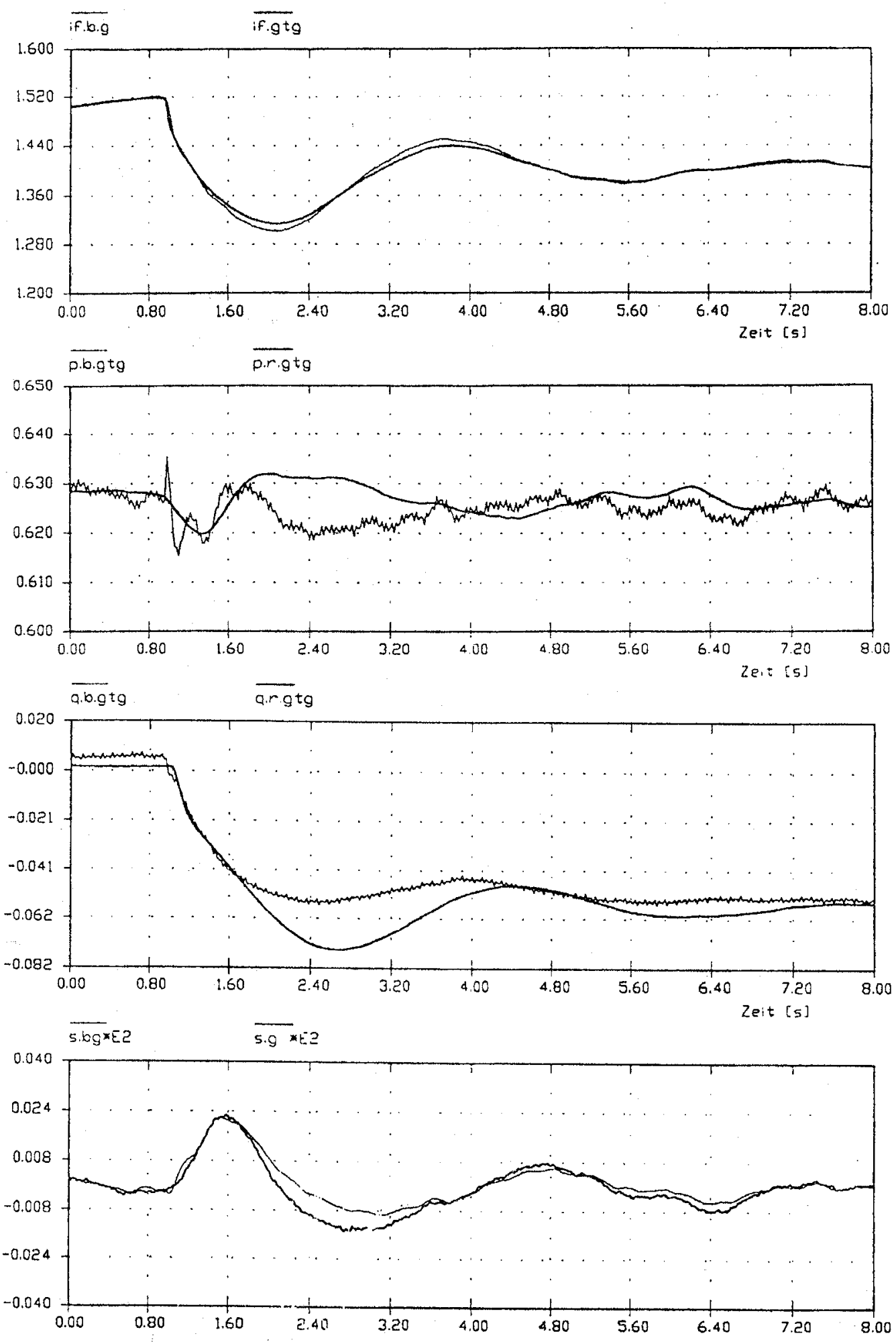

Figure (4) Transient oscillations without additional feedback variables 

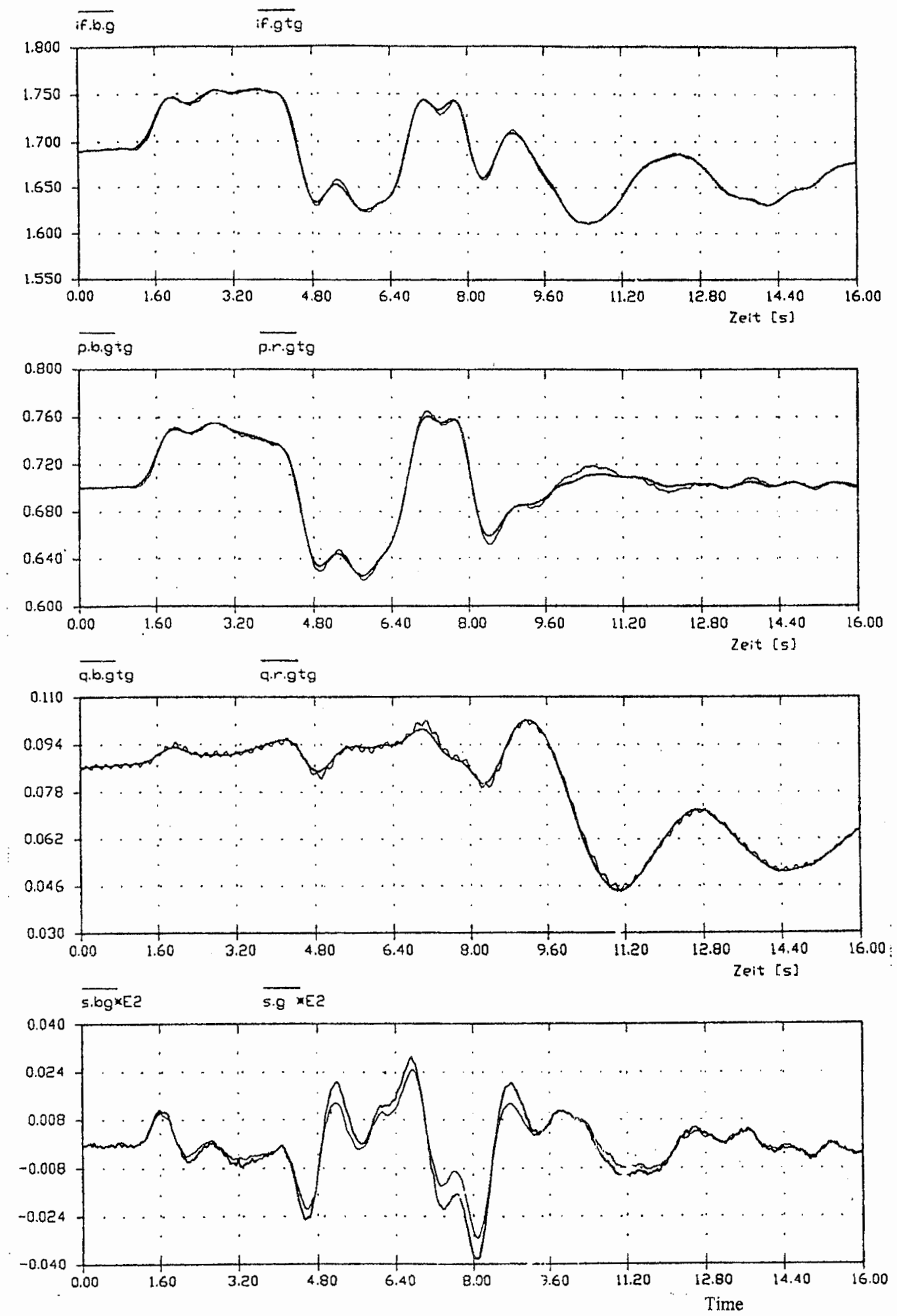

Figure (5) Transient oscillations with additional feedback variables

(5-a): SC2, Amplitude of stator current is used as additional feedback 

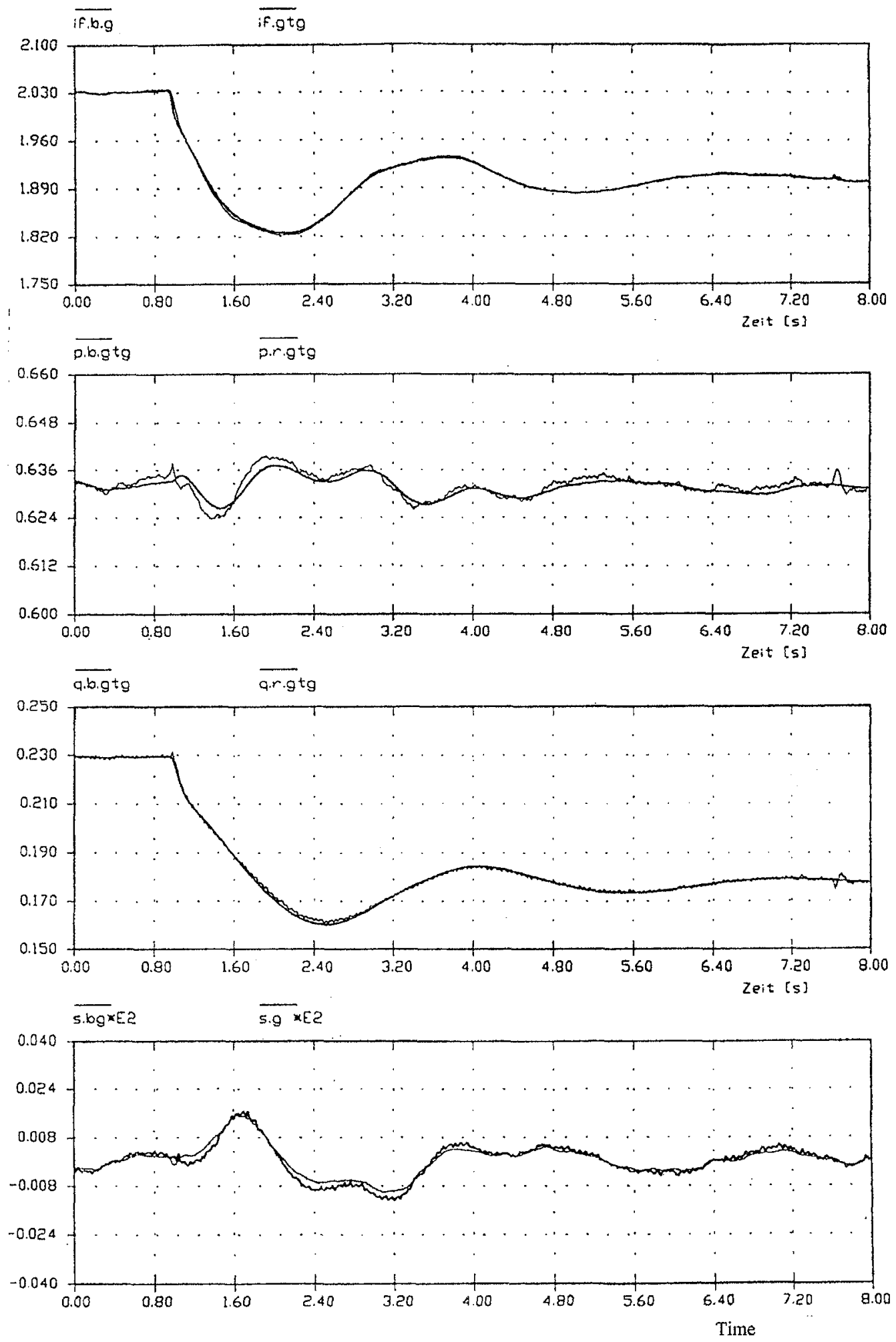

Figure (5) Transient oscillations with additional feedback variables

(5-b): SC8, Reactive power is used as additional feedback 

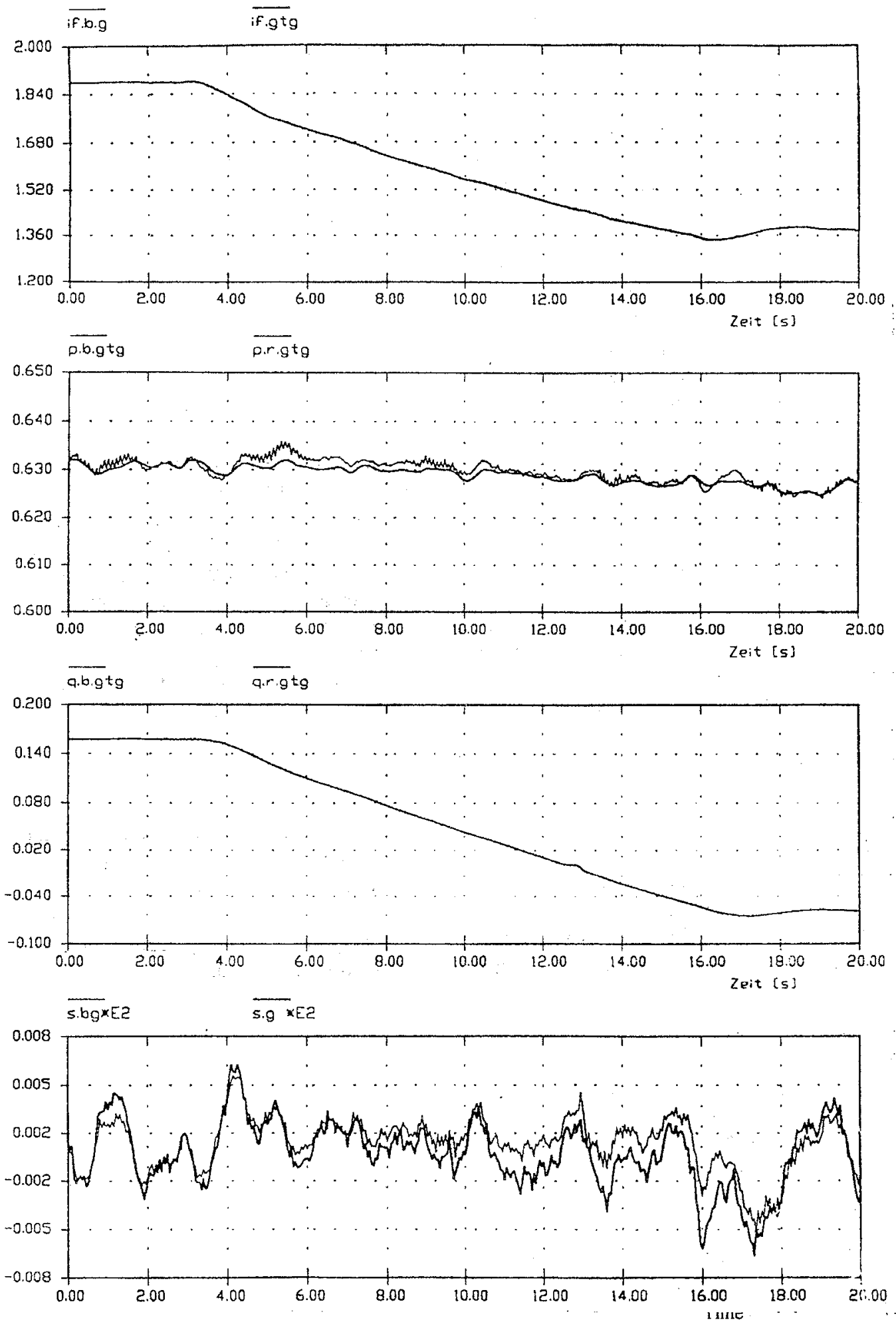

Figure (5) Transient oscillations with additional feedback variables

(5-c): SC1, Real power is used as additional feedback 
SC2: Represent a practical switching case of stepping the transformer from position $4 \rightarrow 3$.

SC3: Represent a practical switching case of stepping the transformer from position $1 \rightarrow 2$.

SC4: Represent a practical switching case of stepping the transformer from position $2 \rightarrow 1$.

SC5: Represent a practical switching case of ramp change in the reference voltage, and so on.

ha1-ha7 : Feedback coefficients (Refer to Eqns. $3.9 \& 3.10$ ).

AV :Average value with the neglecting of very small and very large values.

$\mathrm{OF}_{\mathrm{v}} \quad$ :Objective function without additional feedback.

$\mathrm{OF}_{\text {opt. }} \quad$ : Objective function with additional feedback.

$\mathrm{I}_{\text {opt. }} \quad:$ Improvement $\left(\mathrm{OF}_{\mathrm{opt}} / \mathrm{OF}_{\mathrm{v}}\right)$.

$\mathrm{OF}_{\mathrm{AV}}$. : Objective function with middle value

of the feedback vector.

$\mathrm{I}_{\mathrm{AV}} . \quad$ : Improvement $\left(\mathrm{OF}_{\mathrm{AV}} / \mathrm{OF}_{\mathrm{v}}\right)$.

From these tables, it is clear that an improvement in the observer behavior independent on the additional feedback signals has been reached. The oscillations are also becoming effectively smaller than those without additional feedback signals. Specially good results are noted in case of using the reactive power as feedback signal which also leads to a very improved active power reconstruction. This can be obviously detected from the considerably reduced values obtained of the objective functions (Compare the gray shaded row of Tables (1-a,1-b,1-c.1-d)). Simulation results given in Fig.5 assures such results at different switching cases. The curves of Fig.5, also, show that the use of additional signals give an efficient reduction to the oscillatory states. Again, Fig. (5-b) insures that the best results can be obtained if additional feedback from the reactive power are implemented.

\section{Conclusions}

This paper has proposed experimental realization of optimum algorithms for the determination of the feedback coefficients of a synchronous generator nonlinear observer. Based on real machine measurements and additional feedback signals, the optimum algorithms has been implemented to introduce the required damping of the oscillatory observer states. Results have proved that applying the optimization algorithms with the additional signal from the reactive power leads to minimum states oscillations.

\section{Nomenclature}

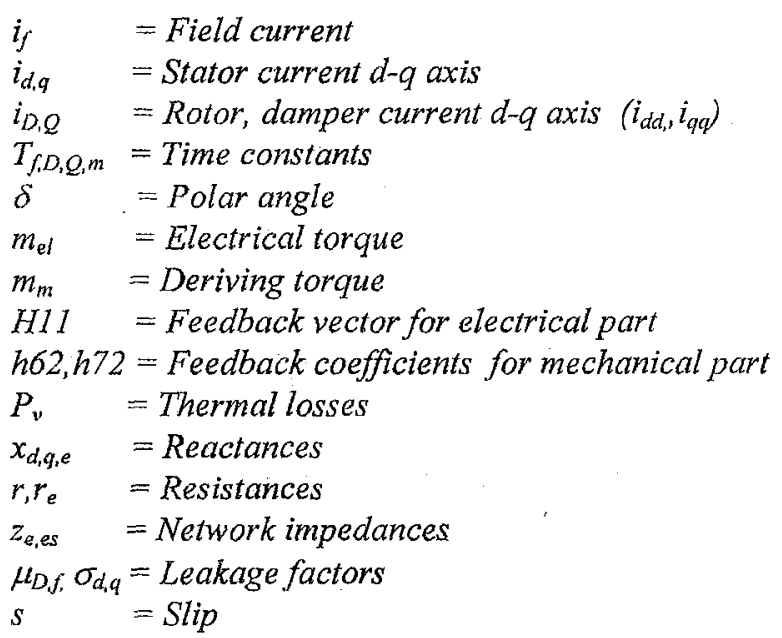




\section{Appendix}

$$
\begin{aligned}
& L=\left[\begin{array}{ccccc}
1 & -x_{d}\left(1-\sigma_{d f}\right) & -\left(1-\mu_{f}\right) & 0 & 0 \\
1 & -\left(x_{d}+x_{e}\right) & -1 & 0 & 0 \\
-\left(1-\mu_{D}\right) & x_{d}\left(1-\sigma_{d D}\right) & 1 & 0 & 0 \\
0 & 0 & 0 & -\left(x_{q}+x_{e}\right) & -1 \\
0 & 0 & 0 & x_{q}\left(1-\sigma_{q}\right) & 1
\end{array}\right] \\
& R=\left[\begin{array}{ccccc}
-1 / T_{f} & 0 & 0 & 0 & 0 \\
0 & \omega\left(r+r_{e}\right) & 0 & \omega\left(x_{q}+x_{e}\right) & -\omega \\
0 & 0 & -1 / T_{D} & 0 & 0 \\
-\omega & \omega\left(x_{d}+x_{e}\right) & \omega & \omega\left(r+r_{e}\right) & 0 \\
0 & 0 & 0 & 0 & -1 / T_{Q}
\end{array}\right]
\end{aligned}
$$

\section{References}

[1] Nour Eldin H.A., Osmain N.

"Robust Nonlinear State Observer for the Synchronous Generator", Congress "Real Time Control of Industrial Processes", Warsaw 1986

[2] Nour Eldin H.A., Osman N.

"Robust Nonlinear Observer for the Synchronous Generator", Foundations of Control Engeneering , Ed. by T.Kaczorek, Vol 12, NO. 1, 11-29, 1987

[3] Osman $N$.

"Nichtlinearer Zustandsbeobachter für die Spannungsregelung des Synchrongenerators", Dissertation, Univ. of Wuppertal, 1990

[4] Nern H.-J., Nour Eldin H.A.

"Survey in Methodology and Real Time Realization of State Observers of Electrical Generators",

IFAC,IMACS

Symposium, MIM S2, Bruxelles, 1990

[5] Nour Eldin H.A., Lerch E. et. al.

"Digitale Simulation der Synchronmaschine mit Zustandsraumdarstellung", ETZ-Archiv, Bd. 2, 1980

[6] Crary S.B.

"Power System Stability", vol 2, Wiley, New York, 1947

[7] Westinghouse Electr. Corp.

"Electrical Transmission and Distribution Reference Book", Pittsburgh, Pa., 1950

[8] Concordia, C

"Synchronous Machines", Wiley, New York, 1951

[9] Laible, Th.

"Theorie der Synchronmaschine im nichtstation ren Betrieb", Springer Verlag, Berlin 1952

[10] Kimbark E.W

"Power System Stability", vol 1, Wiley, New York 1956

[11] Taylor G.D

"Analysis of Synchronous Machines Connected to Power Network", IEE [British], Monograph. Cambridge Univ.

Press, London, 1962

[12] Adkins B

"The General Theorie of Electrical Machines", Chapman and Hall, London, 1964

[13] Anderson P.M.

"Analysis of faulted Power Systems", Iowa State Univ. Press. 1973

[14] Nelles D

"Die Beschreibung der Synchronmaschine für Ausgleichsvorg nge in Drehstromnetzen", Wiss.Ber. AEGTelefunken, 46, 1973

[15] Anderson P.M., Fouad A.A.

"Power System Control and Stability", Vol. 1, 1977

[16] Leonhard W.

"Regelung in der elektrischen Energieversorgung", Teubner Verlag, Stuttgart 1980

[17] Arumugam M, Ramamoorty M.

"A Dynamic Observer for a Synchronous Machine", Int. J. Control, 1972, vol. 15, No 6, 1129-1136

[18] Quintana V.H., Moharrem O.E. 
"Minimal-Order Observers for Synchronous Machine Control", IEEE PES Winter meeting, New York, January 29-

February 3, 1978

[19] Choi San Shing, Lim Choo Min

"On the Design of Luenberger-Type Observers for Single-Machine Infinite-Bus", Electric Power Systems

Research,

$4271-276,1981$

[20] Yamashita K., Taniguchi $T$.

"On the Estimation of the Transient State of a synchronous machine by an optimal observer", Int.J. Control, vol 41,

No 2, 417-428, 1985

[21] Nern, H.-J., Fischer F., Nour Eldin H.A.

"Distributed Realtime State Reconstruction and Visualization for Control and Monitoring of

Turbogenerators",

IFAC International Symp. on Distributed Intelligence Systems, DIS '91, 12-15 August, Arlington, Virginia,

USA

[22] Nern H. -J., Nour Eldin H.A.

"Observer Based Control Scheme of Large Turbogenerators on a Distributed Processor System", IMACS. IFAC

International Symp. on Parallel and Distributed Computing in Engineering Systems, June 23-28,91, Corfu, Greece

[23] Dote, Y

"Application of Modern Control Tecliniques to Motor Control" Proc Of IEEE, Vol.76, No.4, Pp.438-454, April 1988.

[24] Stadfeld,S.

"Das Verfahren zur reglung der Pulsumrichtergespeisten Asynchronmaschine durch. Praedikation und Optemierung in Echtzeit" Diss. Uni-GH- Wuppertal, Germany, 1987.

[25] Abdel-Hamid, A.M.

"Combined Static Var and Voltage control systems" Diss., El-Menoufia Univ.Egypt, 1991.

[26] Nour Eldin, H.A.

"Non-linear stability analysis for restricted Non-linearities Using the Second Method of Liapunov"

2nd.international IFAC-Conference, Pp.561-567, Basel 1963

[27] Nern H.-J., Nour Eldin H.A.

"Animation of Synchronous Generator Dynamics and its State Reconstruction Observers on a Transputer Network",

[FAC - IMACS Symposium MCTS, May 7-10, 1991, Lille, France

[28] Kralmann, $\mathrm{H}$

"Heuristische Optimierung von Simulationsmodellen mit dem pattern-search-algorithmus"

Birkhaeuser Verlag, 1976.

[29] Eckhardt, $\mathrm{H}$.

"Numerische Verfahren in der Energietechnik" Teubner-Studienbuecher, 1980.

[30] Ratschek, H.; Rokne, J.

"New computer methods for global optimization" Ellis Horwood ltd, 1988.

[31] Press, W.H.; Flannery, B.P.; Teukolsky, S.A.; Vetterling, W.T.

"Numerical recipes in C" Cambridge university press, 1988.

[32] F. Fischer

"Software-Realisierung eines echtzeitfaehigen, nichtlinearen Zustandsbeobachter auf einem

Transputernetzwek", Studienarbeit, BUGH-Wuppertal, 1990 
الثوابت المثلى للملاحظ اللاحظى لمولد متز امن عملى باستخدام إشارات إضافية

\section{/ / عبدالحمبذ محمد عبدالحمبد}

يتمـيز المولد التنز امنى بتقاعل غير خطى بين الأداء اللدينـاميكى الكهربسى

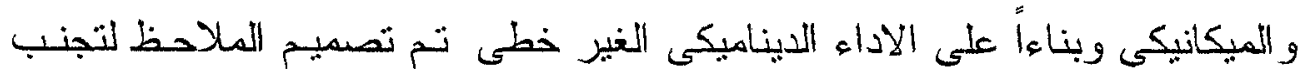

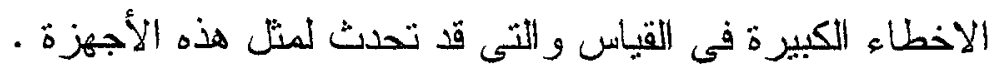

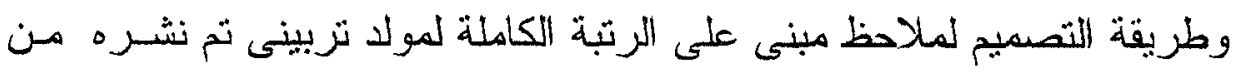

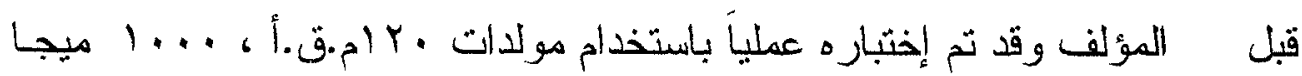

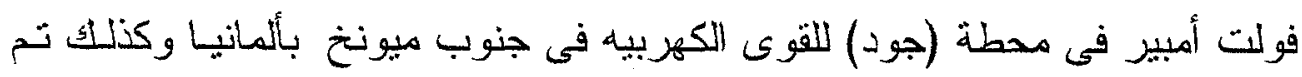
أختباره فى محطة القوى النو اويه (جوسجن)بسويسر او النتائج المقاسه من محطيسات

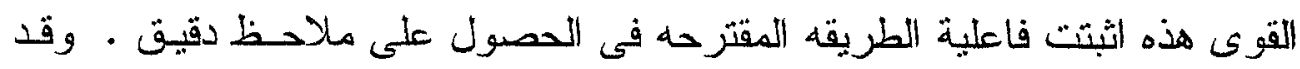

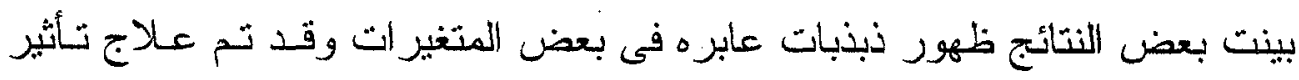

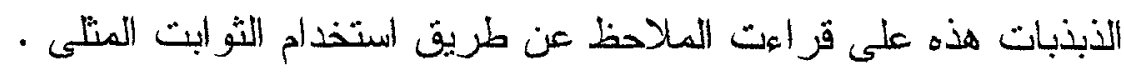

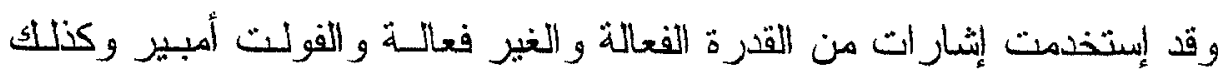

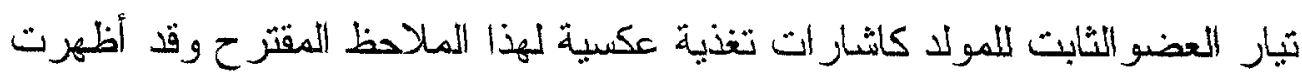

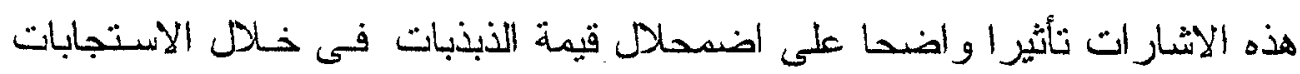
العابرة. 